\title{
Effect of surgical delay on early mortality in patients with femoral neck fracture
}

\author{
Andor Sebestyén • Imre Boncz • János Sándor • \\ József Nyárády
}

Received: 11 December 2006 /Revised: 21 December 2006 / Accepted: 22 December 2006 / Published online: 24 February 2007

(C) Springer-Verlag 2007

\begin{abstract}
The aim of this study was to investigate the relationship between the delay between surgical treatment and mortality occurring within 30 days post-injury in patients aged 60 or older with femoral neck fracture. Data derive from the nationwide database of the National Health Insurance Fund Administration. Logistic regression analysis was performed to analyse the relationship between 30 -day mortality and surgical delay in four groups of patients operated on within $12 \mathrm{~h}$, between 12-24 h, 24-48 h or over $48 \mathrm{~h}$ post-injury. There were 3,777 patients involved in the study. Mortality rates in the four groups were $7.7 \%, 10.5 \%$, $10.5 \%$ and $9.4 \%$, respectively. Univariate logistic regression analysis revealed a statistically significant increase in the mortality risk in the 12-24-h treatment group compared to the group treated within $12 \mathrm{~h}$ (odds ratio, $\mathrm{OR}_{12-24 \mathrm{~h}}=1.413$, confidence interval, $\left.\mathrm{CI}_{12-24 \mathrm{~h}}: 1.032-1.935 ; \mathrm{p}=0.031\right)$.
\end{abstract}

\footnotetext{
A. Sebestyén $(\bowtie)$

County Baranya Health Insurance Fund Administration,

Pécs 7623 Nagy Lajos király út 3., Hungary

e-mail: Sebestyen.Andor@dravanet.hu

I. Boncz

National Health Insurance Fund Administration (OEP),

Budapest, Hungary

I. Boncz

Institute of Diagnostics and Management,

University of Pécs, Pécs, Hungary

J. Sándor

Department of Epidemiology,

University of Pécs, Pécs, Hungary

J. Nyárády

Department of Traumatology and Hand Surgery,

University of Pécs, Pécs, Hungary
}

According to multiple regression analysis, all three groups (12-24 h, 24-48 h and over $48 \mathrm{~h}$ ) showed a trend to increased mortality risks, but this was not statistically significant $\left(\mathrm{OR}_{12-24 \mathrm{~h}}=1.301, \mathrm{CI}_{12-24 \mathrm{~h}}: 0.945-1.791, \mathrm{p}=\right.$ $0.106 ; \mathrm{OR}_{24-48 \mathrm{~h}}=1.384, \mathrm{CI}_{24-48 \mathrm{~h}}: 0.932-2.056, \mathrm{p}=0.108$; $\left.\mathrm{OR}_{>48 \mathrm{~h}}=1.246, \mathrm{CI}_{>48 \mathrm{~h}}: 0.950-1.635, \mathrm{p}=0.113\right)$. We can conclude that sex, age and accompanying diseases significantly influenced early mortality, while early post-operative complications did not have a significant impact on the mortality risks.

Résumé Le but de cette étude est d'analyser les relations entre le délai séparant le traitement chirurgical et le décès survenant 30 jours après un traumatisme chez des patients âgés de 60 ans ou plus présentant une fracture du col du fémur. Les données ont été analysées à partir de la Base Nationale de donnée. Une analyse informatique a été réalisée à partir d'une mortalité survenant 30 jours après le traitement. Les patients ont été divisés en 4 groupes, ceux opérés à la $12 \mathrm{~h}$, entre 12 et $24 \mathrm{~h}$, entre 24 et $48 \mathrm{~h}$ et après $48 \mathrm{~h}$; 3,777 patients ont été inclus dans cette étude. La mortalité dans les 4 groupes a été respectivement de $7.7 \%$, $10.5 \%, 10.5 \%$ et $9.4 \%$. L'analyse a révélé qu'il existait une augmentation significative de la mortalité dans le groupe 12-24 h comparé au groupe traité avant $12 \mathrm{~h}$ (odds ratio, OR 12-24 $\mathrm{h}=1.413$, avec un intervalle de confiance, CI 12-24 h: $1.032-1.935, \mathrm{p}=0.031)$. Selon l'analyse par régression variable, ces trois groupes $(12-24 \mathrm{~h}, 24-48 \mathrm{~h}$ et plus de $48 \mathrm{~h}$ ) ont tendance a montré une augmentation du risque de mortalité mais cette différence n'est pas significative (OR 12-24 h=1.301, CI 12-24 h: 0.945$1.791, \mathrm{p}=0.106$; OR $24-48 \mathrm{~h}=1.384$ CI $24-48 \mathrm{~h}: 0.932$ $2.056, \mathrm{p}=0.108 ;$ OR $>48 \mathrm{~h}=1.246, \mathrm{CI}>48 \mathrm{~h}: 0.950-1.635$, $\mathrm{p}=0.113$ ). Nous pouvons conclure que le sexe, l'âge et les pathologies et co-morbidité influencent de façon signifi- 
cative la mortalité précoce alors que les complications post-opératoires précoces n'ont pas d'impact significatif sur le risque de mortalité.

\section{Introduction}

Factors influencing mortality in the elderly population following femoral neck fracture have been widely described in the literature. The parameters most often investigated are age, gender, surgical delay [12], co-morbidity [13] and post-operative complications [16], while less literature exists describing the effect of the type and location of fractures [6], type of institutions providing the treatment, day of admission [5], delayed post-operative mobilisation [18] and others.

Several authors have investigated the significance of the delay in surgery; opinions concerning its importance, however, vary widely. Decrease in the mortality risks could be demonstrated when treatment was provided within $24 \mathrm{~h}$ $[15,20]$ or within $6 \mathrm{~h}$ post-injury [3], while other studies found the lack of correlation [8] between early treatment (within $24 \mathrm{~h}$ ) and mortality. Several professional guidelines $[14,17]$ recommend surgical treatment within $24 \mathrm{~h}$ in order to decrease mortality and other complications.

In Hungary, studies performed mainly on small populations have investigated the 5-year survival rates of femoral fractures [7], described mortality in relation to different surgical treatments and rehabilitation [2] or the effect of the delay in surgery $[4,19]$. Only a limited number of studies has been extended to larger populations. This study was intended to supply nationwide data regarding the impact of early versus delayed surgical treatment on early mortality associated with femoral neck fractures.

Our primary aim was to evaluate the relationship between surgical delay and early mortality (within 30 days), specifically to determine if the prognosis-improving effect of early treatment can be detected in the Hungarian circumstances in elderly patients (aged 60 or over) suffering femoral neck fracture. To a lesser extent, the role of other prognostic factors was also investigated.

\section{Materials and methods}

Data were obtained from the database of the National Health Insurance Fund Administration (NHIFA) based on the 10th revision of the International Classification of Diseases (ICD). A nationwide questionnaire survey supported by the Professional Colleges of Traumatology and Orthopaedics was performed to validate the data and to obtain additional data on the care. Patients diagnosed with fractured necks of the femur (ICD code S7200) and discharged from inpatient care in the year 2000 after primary surgical treatment were included in the study. Cases without a valid social insurance identity number necessary for identification or cases with incomplete or contradictory information provided upon filling out the questionnaire were excluded from further evaluation.

Mortality rates resulting from mortality within 30 days post-injury were evaluated in four groups regarding the time elapsed between the fracture and the definitive surgery: within $12 \mathrm{~h}$, between 12-24 h, 24-48 h and over $48 \mathrm{~h}$.

Co-morbidities were defined as diseases already present at the time of the accident or those diagnosed during the time in hospital, but not directly related to the fracture. (Their detailed influence will be evaluated in another study.)

Early complications were defined as cases requiring further interventions relating to the primary surgery of the fracture and occurring within 30 days post-surgery during the same hospital stay (bleeding leading to re-operation, evacuation of haematomas, re-operations due to secondary dislocation, etc.).

Univariate and multiple logistic regression analyses were performed to investigate the impact of different parameters (delay in surgery, age, gender, presence of comorbidities and early complications) on early post-admission mortality. The prognosis determining the importance of these factors was described with odds ratios (OR) and their $95 \%$ confidence intervals (CI). Reference values were defined as follows: treatment provided within $12 \mathrm{~h}$ postinjury, male gender, lack of co-morbidities and lack of early complications.

\section{Results}

Description of cases

The number of patients meeting the case definition criteria was 3,777 with the average age of $77.97( \pm 8.52$, median: 78). The proportions of patients aged $60-69,70-79,80-89$ and 90 or over were $17.3 \%, 40.9 \%, 32.6 \%$ and $9.2 \%$, respectively. The proportion of female patients was $75.7 \%$. Co-morbidities were present in $91.2 \%$, and $2.2 \%$ of the patients needed further intervention during the hospitalisation period due to complications related to the primary treatment of the fracture.

Regarding the four groups investigated, surgery was performed within $12 \mathrm{~h}$ in 1,659 cases $(43.9 \%)$, between 12 and $24 \mathrm{~h}$ in 620 cases $(16.4 \%)$, between 24 and $48 \mathrm{~h}$ in 343 cases $(9.1 \%)$ and over $48 \mathrm{~h}$ in 1,155 cases $(30.6 \%)$. Among the groups, the average age varied between 77.95 78.01 years with a median of 78 years in each group (Table 1). The proportions of patients aged 60-69, 70-79, $80-89$ and 90 or over varied from $15.6-18.9 \%, 37.9-42.2 \%$, 
Table 1 Demographic and clinical parameters of 3,777 elderly patients with fractured femoral neck in relation to surgical delay

\begin{tabular}{|c|c|c|c|c|c|}
\hline Surgical delay & $0-12 \mathrm{~h}$ & $12-24 \mathrm{~h}$ & $24-48 \mathrm{~h}$ & $>48 \mathrm{~h}$ & All patients \\
\hline $\begin{array}{l}\text { Number of Patients: } \\
\text { Age }\end{array}$ & 1,659 & 620 & 343 & 1,155 & 3,777 \\
\hline Average \pm SD (years) & $77.975 \pm 8.517$ & $77.954 \pm 8.474$ & $77.970 \pm 8.472$ & $78.006 \pm 8.466$ & $77.975 \pm 8.517$ \\
\hline Median (years) & 78 & 78 & 78 & 78 & 78 \\
\hline Minimum-maximum (years) & $60-102$ & $60-100$ & $60-100$ & $60-101$ & $60-102$ \\
\hline Rate of woman $(\%)$ & 76.4 & 75 & 75.5 & 75.3 & 75.7 \\
\hline \multicolumn{6}{|l|}{ Rate of age groups (\%) } \\
\hline $60-69$ years & 16.9 & 15.6 & 18.9 & 18.3 & 17.3 \\
\hline $70-79$ years & 42.2 & 37.9 & 39.4 & 41.2 & 40.9 \\
\hline $80-89$ years & 32.5 & 35 & 30.9 & 32 & 32.6 \\
\hline$<90$ years & 8.4 & 11.5 & 10.8 & 8.5 & 9.2 \\
\hline Rate of co-morbidities (\%) & 90.2 & 93.1 & 92.7 & 91.2 & 91.2 \\
\hline Rate of early complications (\%) & 1.8 & 2.4 & 1.5 & 2.9 & 2.2 \\
\hline
\end{tabular}

$30.9-35 \%$ and $8.4-11.5 \%$, respectively. The proportion of female patients ranged between $75-76.4 \%$. Co-morbidities were present in $90.2-93.1 \%$, and the rate of early complications varied between $1.5-2.9 \%$.

Statistical analysis of mortality rates

Table 2 demonstrates the distribution of raw mortality rates occurring within 30 days after femoral neck fracture in patients aged 60 or over in relation to the time delay until surgery was performed.

The mortality rate observed within 30 days in the case of all patients included in the study was $8.9 \%$. With regard to the different prognostic factors investigated, mortality rates could be observed as follows: in the different genders: $10.9 \%$ and $8.3 \%$ (male and female populations, respectively); in the different age groups: $4.1 \%, 7.6 \%$, $10.2 \%$ and $19.4 \%$ (patients aged $60-69,70-79,80-89$ and 90 or over, respectively); in the presence of co-morbidities: $9.7 \%$ and $2.1 \%$ in the lack of those; on the appearance of early complications: $9.5 \%$ and $8.9 \%$ in the lack of those.

In relation to the time elapsed until surgery, the mortality rates within 30 days were $7.7 \%$ when treatment was provided within $12 \mathrm{~h}, 10.5-10.5 \%$ when surgery was performed between $12-24 \mathrm{~h}$ or $24-48 \mathrm{~h}$, and $9.4 \%$ when surgery was provided over $48 \mathrm{~h}$ post-injury.

The average mortality rates within 30 days in relation to the prognostic factors and the time elapsed until the operation were observed as follows (in order of the four groups): regarding gender, in males $8.9-13.5-14.3-11.2 \%$ and in females 7.3-9.5-9.3-8.9\%; regarding age, in patients aged $60-69,3.6-4.1-4.6-4.7 \%$, in patients aged 70-79, 6.7-8.9-

Table 2 Mortality rates within 30 days in 3,777 elderly patient with femoral neck fracture in relation to the surgical delay

\begin{tabular}{|c|c|c|c|c|c|}
\hline Surgical delay & $0-12 \mathrm{~h}$ & $12-24 \mathrm{~h}$ & $24-48 \mathrm{~h}$ & $>48 \mathrm{~h}$ & All patients \\
\hline \multicolumn{6}{|l|}{ Sex } \\
\hline Male & $35 / 392(8.9 \%)$ & $21 / 155(13.5 \%)$ & $12 / 84(14.3 \%)$ & $32 / 285(11.2 \%)$ & $100 / 916(10.9 \%)$ \\
\hline Female & $92 / 1,267(7.3 \%)$ & $44 / 465(9.5 \%)$ & $24 / 259(9.3 \%)$ & $77 / 870(8.9 \%)$ & $237 / 2,861(8.3 \%)$ \\
\hline \multicolumn{6}{|l|}{ Age group } \\
\hline $60-69$ years & $10 / 281(3.6 \%)$ & 4/97 (4.1\%) & $3 / 65(4.6 \%)$ & $10 / 211(4.7 \%)$ & $27 / 654(4.1 \%)$ \\
\hline $70-79$ years & $47 / 700(6.7 \%)$ & $21 / 235(8.9 \%)$ & $10 / 135(7.4 \%)$ & $39 / 476(8.2 \%)$ & $117 / 1,546(7.6 \%)$ \\
\hline $80-89$ years & $46 / 539(8.5 \%)$ & $27 / 217(12.4 \%)$ & $15 / 106(14.2 \%)$ & $38 / 370(10.3 \%)$ & $126 / 1,232(10.2 \%)$ \\
\hline$<90$ years & $24 / 139(17.3 \%)$ & $13 / 71(18.3 \%)$ & $8 / 37(21.6 \%)$ & $22 / 98(22.4 \%)$ & $67 / 345(19.4 \%)$ \\
\hline \multicolumn{6}{|l|}{ Co-morbidities } \\
\hline Yes & $124 / 1,498(8.3 \%)$ & $64 / 577(11.1 \%)$ & $36 / 318(11.3 \%)$ & $106 / 1,053(10.1 \%)$ & $333 / 3,446(9.7 \%)$ \\
\hline No & $3 / 161(1.9 \%)$ & $1 / 43(2.3 \%)$ & $0 / 25(0 \%)$ & $3 / 102(2.9 \%)$ & $7 / 331(2.1 \%)$ \\
\hline \multicolumn{6}{|c|}{ Early complications } \\
\hline Yes & $1 / 30(3.3 \%)$ & $2 / 15(13.3 \%)$ & $0 / 5(0 \%)$ & $5 / 34(14.7 \%)$ & $8 / 84(9.5 \%)$ \\
\hline No & $126 / 1,629(7.7 \%)$ & $63 / 605(10.4 \%)$ & $36 / 338(10.7 \%)$ & $104 / 1,121(9.3 \%)$ & $329 / 3,693(8.9 \%)$ \\
\hline All patients & $127 / 1,659(7.7 \%)$ & $65 / 620(10.5 \%)$ & $36 / 343(10.5 \%)$ & $109 / 1,155(9.4 \%)$ & $337 / 3,777(8.9 \%)$ \\
\hline
\end{tabular}

Number of early death cases/number of all patients treated; mortality rate (\%). 
Table 3 The relation of mortality within 30 days to particular prognostic factors in logistic regression models

\begin{tabular}{|c|c|c|c|c|c|c|}
\hline \multirow[t]{2}{*}{ Prognostic factors } & \multicolumn{3}{|c|}{ Univariate analysis } & \multicolumn{3}{|c|}{ Multivariate analysis } \\
\hline & OR & (CI) & $\mathrm{p}$ value & OR & $(\mathrm{CI})$ & $\mathrm{p}$ value \\
\hline Sex (male/female) & 0.737 & $(0.576-0.943)$ & 0.015 & 0.635 & $(0.494-0.818)$ & $<0.001$ \\
\hline Age (years) & 1.062 & $(1.047-1.077)$ & $<0.001$ & 1.061 & $(1.046-1.077)$ & $<0.001$ \\
\hline Co-morbidities (yes/no) & 4.902 & $(2.299-10.453)$ & $<0.001$ & 4.182 & $(1.953-8.954)$ & $<0.001$ \\
\hline Early complications (yes/no) & 1.076 & $(0.515-2.250)$ & 0.845 & 1.268 & $(0.599-2.681)$ & 0.535 \\
\hline Delay $(12-24 \mathrm{~h} / 0-12 \mathrm{~h})$ & 1.413 & $(1.032-1.935)$ & 0.031 & 1.301 & $(0.945-1.791)$ & 0.106 \\
\hline Delay $(24-48$ h/0-12 h) & 1.415 & $(0.958-2.089)$ & 0.081 & 1.384 & $(0.932-2.056)$ & 0.108 \\
\hline Delay (over 48 h/0-12 h) & 1.257 & $(0.962-1.643)$ & 0.094 & 1.246 & $(0.950-1.635)$ & 0.113 \\
\hline
\end{tabular}

(OR: odds ratio, CI: $95 \%$ confidence interval, p: significance of the statistical test)

$7.4-8.2 \%$, in patients aged $80-89,8.5-12.4-14.2-10.3 \%$, and in patients aged 90 or over, $17.3-18.3-21.6-22.4 \%$; in the presence of co-morbidities, 8.3-11.1-11.3-10.1\%, while in the lack of those, 1.9-2.3-0-2.9\%; on appearance of early complications, 3.3-13.3-0-14.7\%, while in the lack of those, 7.7-10.4-10.7-9.3\%.

Table 3 summarises the odds ratios of mortality risks occurring within 30 days calculated by univariate and multiple logistic regression analyses. According to both the univariate and the multiple analyses, gender, age and comorbidities had a significant impact on early mortality. Specifically, male gender, older age and the presence of accompanying diseases were associated with higher mortality risks (gender: $p_{\text {univariate }}=0.0015, p_{\text {multiple }}<0.001$; age: $\mathrm{p}<0.001$, co-morbidities: $\mathrm{p}<0.001)$. Analyses did not reveal correlation between the presence of early complications and mortality risks ( $p_{\text {univariate }}=0.845 ; p_{\text {multiple }}=0.535$ ).

According to the univariate analysis, mortality risks in the group treated with a 12-24 h delay were significantly higher in relation to those treated within $12 \mathrm{~h}\left(\mathrm{OR}_{12-24 \mathrm{~h}}=\right.$ $\left.1.413, \mathrm{CI}_{12-24 \mathrm{~h}}: 1.032-1.935 ; \mathrm{p}=0.031\right)$. The increase in the mortality risks in patients treated with a $24-48$-h or over 48 -h delay was close to statistical significance $\left(\mathrm{OR}_{24-48 \mathrm{~h}}=\right.$ 1.415, $\mathrm{CI}_{24-48 \mathrm{~h}}$ : 0.958-2.089, $\mathrm{p}=0.081 ; \mathrm{OR}_{>48 \mathrm{~h}}=1.257$, $\mathrm{CI}_{>48 \mathrm{~h}}$ : 0.962-1.643, $\left.\mathrm{p}=0.094\right)$. According to multiple regression, in all three groups $(12-24 \mathrm{~h} ; 24-48 \mathrm{~h}$; over $48 \mathrm{~h}$ ), a trend to increased mortality risks could be detected, but this was not statistically significant in any of the groups $\left(\mathrm{OR}_{12-24 \mathrm{~h}}=1.301, \mathrm{CI}_{12-24 \mathrm{~h}}\right.$ : 0.945-1.791, $\mathrm{p}=$ $0.106 ; \mathrm{OR}_{24-48 \mathrm{~h}}=1.384 \mathrm{CI}_{24-48 \mathrm{~h}}: 0.932-2.056, \mathrm{p}=0.108$; $\mathrm{OR}_{>48 \mathrm{~h}}=1.246, \mathrm{CI}_{>48 \mathrm{~h}}$ : 0.950-1.635, $\left.\mathrm{p}=0.113\right)$.

\section{Discussion}

In a study of the 3,777 elderly patients who met the case definition criteria, the average mortality rate occurring within 30 days post-admission was $8.9 \%$. Regarding the time elapsed between the fracture and the definitive surgical treatment, early surgery was associated with a lower rate of mortality $(7.7 \%$, with case numbers sufficient for statistical analysis regarding each prognostic factor), while delayed treatment was associated with mortality rates above the average (10.5-10.5\% in the case of 12-24 $\mathrm{h}$ and $24-48 \mathrm{~h}$ delay, and $9.4 \%$ in the case of $48 \mathrm{~h}$ or longer delay).

The study revealed that sex, age and accompanying diseases significantly influence early mortality, while early complications related to the primary treatment did not have a significant impact on the mortality risks.

Chariyalertsak et al. found that the 3-, 6- and 12-month survival rates of patients with hip fracture were $91 \%, 88 \%$ and $83 \%$, respectively, and male sex, age over 80 years, presence of chronic illnesses, poor pre-fracture walking ability and nonoperative treatment proved to be significant predictors of mortality [1].

Although our results did not demonstrate statistically significant correlation between the delay of treatment and mortality risks, the observed, approximately 30\% mortality increasing effect of treatments performed beyond $12 \mathrm{~h}$ (with $\mathrm{p}$ values close to significant) argues for the vital importance of the earliest possible treatment.

Our results highlight the importance of further evaluating the reasons underlying the delay in surgical treatment (problems during treatment, difficulties in surgical access, co-morbidity, etc.), especially in cases when surgery is performed with a $24-\mathrm{h}$ or longer post-injury delay $(39.7 \%$ of all patients), in order to determine factors that influence the prognostic significance of surgical delay in the case of different patient groups. In the course of comparative investigations evaluating the impact of prognostic factors on early mortality, monitoring of other parameters, such as the general condition, presence of musculo-skeletal disabilities and some anaesthetic parameters (ASA grade) measured at the time of admission, should also be considered.

Some factors significantly influencing the patients' life expectancies were presumably not or not properly included in our study, resulting, in spite of the relatively large case 
numbers, in wide confidence intervals in cases with a treatment delay over $12 \mathrm{~h}$ post-injury. Detailed analysis of co-morbidity would probably help to define more homogenous case groups that could be statistically more effectively investigated.

In the future, these considerations may contribute to defining the factors that influence the prognostic value of treatment delay in cases of different patients groups. Despite the factors limiting our results, this study, as with several international guidelines [14, 17], emphasises the importance of the earliest possible treatment, because immobilisation resulting from femoral fractures has several harmful effects endangering life expectancy even in the short run, not to mention the occurrence of late vascular complications of the femoral neck.

To justify the significance of the future directions our studies aim to follow, we underline the importance of previous studies that observed not only the strong correlation between mortality and treatment performed within $24 \mathrm{~h}$, but also found the favourable effect of surgery carried out within $6 \mathrm{~h}$ on mortality and other complication rates $[9-11,19]$.

Conflict of interest statement None.

Source of funding: none.

\section{References}

1. Chariyalertsak S, Suriyawongpisal P, Thakkinstain A (2001) Mortality after hip fracture in Thailand. Int Orthop 25:294-297

2. Cserháti P, Fekete K, Berglund-Rödén M et al (2002) Hip fractures in Hungary and Sweden-differences in treatment and rehabilitation. Int Orthop 26:222-228

3. Dorotka R, Schoechtner H, Buchinger W (2003) The influence of immediate surgical treatment of proximal femoral fractures on mortality and quality of life: operation within $6 \mathrm{~h}$ of the fracture versus later than $6 \mathrm{~h}$. J Bone Joint Surg Br 85-B:1107-1113

4. Fekete K, Laczkó T, Flóris I et al (2002) Treatment of femoral neck fractures in Hungary with the Manninger screw. Injury 33 (Suppl 3):19-23
5. Foss NB, Kehlet H (2006) Short-term mortality in hip fracture patients admitted during weekends and holidays. J Anaesth $\mathrm{Br}$ 96:450-454

6. Kanis JA, Johnell O, De Laet C, Jonsson B, ORen A, Ogelsby AK (2002) International variations in hip fracture probabilities: implications for risk assessment. J Bone Miner Res 17:1237-1244

7. Kazár Gy, Cserháti P, Melly A, Manninger J, Kádas I (1997) Fiveyear follow-up of patients with femoral neck fractures. Orv Hetil 138:3173-3177

8. Majumdar SR, Beaupre LA, Johnston DW, Dick DA, Cinats JG, Jiang HX (2006) Lack of association between mortality and timing of surgical fixation in elderly patients with hip fracture: results of a retrospective population-based cohort study. Med Care 44:552-559

9. Manninger J, Kazar G, Fekete G et al (1985) Avoidance of avascular necrosis of the femoral head, following fractures of the femoral neck, by early reduction and internal fixation. Injury $16: 437-448$

10. Manninger J, Kazar G, Fekete G et al (1989) Significance of urgent (within $6 \mathrm{~h}$ ) internal fixation in the management of fractures of the femur. Injury 20:101-105

11. Manninger J, Kazar G, Fekete K et al (1993) Weitere ergebnisse der dringlichen osteosyntesen bei schenkelhalsfrakturen-senkung des prozentuellen anteiles der kopfnekrosen-bedeutung der 6-stunden-grenze. Hefte zu der Unfallchirurg 230:365-369

12. Moran CG, Wenn RT, Sikand M, Taylor AM (2005) Early mortality after hip fracture: is delay before surgery important? J Bone Joint Surg Am 87:483-489

13. Muraki S, Yamamoto S, Ishibashi H, Nakamura K (2006) Factors associated with mortality following hip fracture in Japan. J Bone Miner Metab 24:100-104

14. New Zeeland Guidelines Group (2003) Acute management and immediate rehabilitation after hip fracture amongst people aged 65 years and over. NZGG, Wellington

15. Perez JV, Warwick DJ, Case CP et al (1995) Death after proximal femoral fracture-an autopsy study. Injury 26:237-240

16. Roche JJW, Wenn RT, Sahota O, Moran CG (2005) Effect of comorbities and postoperative complications on mortality after hip fracture in elderly people: prospective observational cohort study. BMJ 331:1374-1376

17. Scottish Intercollegiate Guidelines Network (2002) Prevention and management of hip fracture in older people. A national clinical guideline. SIGN, Edinburgh

18. Siu AL, PenrOR JD, Boockvar KS, Koval K, Strauss E, Morrison RS (2006) Early ambulation after hip fracture effects on function and mortality. Arch Intern Med 166:766-771

19. Szita J, Cserháti P, Bosch U et al (2002) Intracapsular femoral neck fractures: the importance of early reduction and stable osteosynthesis. Injury 33(Suppl 3):41-46

20. Weller I, Wai EK, Jaglal S, Kreder HJ (2005) The effect of hospital type and surgical delay on mortality after surgery for hip fracture. J Bone Joint Surg Br 87-B:361-366 